\title{
O mercado brasileiro de Energia Elétrica Livre: um estudo de caso na indústria de Shopping Center sob a ótica da gestão eficiente dos recursos financeiros
}

\author{
Crislane Soares Costa ${ }^{1}$; Elane Lopes de Oliveira ${ }^{2}$, Josiano Cesar de Sousa ${ }^{3}$
}

\begin{abstract}
Resumo: Este artigo apresenta conceitos referentes ao Mercado Livre de Energia Brasileiro, com enfoque nos consumidores especiais e define a estruturação institucional do Setor Elétrico Brasileiro. Para sua elaboração, utilizou-se o método de estudo de caso, através de uma pesquisa exploratória realizada em um condomínio empresarial (shopping Center) que pertenceu ao mercado cativo e realizou a migração para o mercado livre de energia de elétrica. O objetivo desta pesquisa é analisar a viabilidade financeira da migração de um condomínio varejista do mercado cativo para o mercado de energia elétrica livre, sob a ótica da gestão eficiente dos recursos financeiros. Como resultado, o estudo realizado comprovou a viabilidade financeira da adesão ao mercado livre, através da análise do ponto de equilíbrio financeiro, possibilitando previsibilidade orçamentaria e uma melhor gestão dos recursos financeiros e quantificaram a redução de custos com o fornecimento de energia elétrica através da a migração do ambiente de contratação regulada para o ambiente de contratação livre. Ao final, o estudo apresenta suas limitações e as recomendações para o desenvolvimento de futuras pesquisas.
\end{abstract}

Palavras-chave: Mercado Livre de Energia. Mercado Cativo. Gestão. Recursos Financeiros.

\section{The Brazilian free electric market: a case study in the Shopping Center industry from the point of view of the efficient management of financial resources}

\begin{abstract}
This article presents concepts related to the Brazilian Free Energy Market, focusing on the special consumers and defines the institutional structure of the Brazilian Electricity Sector. For its elaboration, the case study method was used, through an exploratory survey carried out in a business condominium (shopping center) that belonged to the captive market and carried out the migration to the free market of electric energy. The objective of this research is to analyze the financial viability of the migration of a retail condominium from the captive market to the free electric power market, from the perspective of efficient management of financial resources. As a result, the study carried out proved the financial viability of free market adherence, through the analysis of the financial equilibrium, enabling budget predictability and better management of financial resources and quantified the reduction of costs with the supply of electricity through the migration from the regulated contracting environment to the free contracting environment. At the end, the study presents its limitations and recommendations for the development of future research.
\end{abstract}

Keywords: Free Energy Market. Captive. Market. Financial Resources Management.

\footnotetext{
${ }^{1}$ Bacharel em Administração. Unidade de Ensino Superior do Sul do Maranhão - UNISULMA. admcrislanesoares@gmail.com;

${ }^{2}$ Bacharel em Administração. Unidade de Ensino Superior do Sul do Maranhão - UNISULMA elanelopesdeoliveira@yahoo.com.br;

${ }^{3}$ Mestre em Administração. Unidade de Ensino Superior do Sul do Maranhão - UNISULMA josianocesar@hotmail.com.
} 


\section{Introdução}

A energia elétrica representa um dos principais insumos na cadeia produtiva de um país, servindo como indicador de desenvolvimento e qualidade, uma vez que se faz necessária na vida de todos (GERNERGIA, 2016). Porém, para que isso aconteça é preciso uma longa cadeia de produção e transporte.

A energia movimenta o mundo e dela as empresas dependem para a produção, comercialização e distribuição de seus produtos (OLIVEIRA, 2017). Por essa razão, a redução de gastos com energia é buscada por grandes consumidores, como indústrias, comercio e empresas, uma vez que representa um dos principais insumos na cadeia produtiva do país.

Há cerca de 20 anos iniciou-se uma profunda transformação no Setor Elétrico Brasileiro por parte do governo, com intuito de propiciar uma desverticalização do setor e impulsionar a competitividade. Nesta hodierna conjuntura surge um novo mercado que propende a ser o futuro da categoria, o mercado livre de energia (TOLMASQUIM, 2015).

A motivação para a realização deste estudo é o fato do tema "mercado livre de energia elétrica" ainda ser um assunto pouco discutido no ambiente acadêmico, como também na sociedade em geral. Partindo desse pressuposto, a pesquisa faz um levantamento de informações a respeito do ambiente de contratação livre e energia elétrica no país. Considerando o fato de que a energia elétrica, em se tratando de custos condominiais, representa grande participação na composição geral dos custos operacionais de um shopping center, com base nas variáveis e indicadores apontados nesta pesquisa, ancorado nas áreas de gestão de custos e contabilidade gerencial. A presente pesquisa tem como objetivo geral analisar a viabilidade financeira da migração de um consumidor empresarial do mercado cativo para o mercado de energia elétrica livre, sob a ótica da gestão eficiente dos recursos financeiros.

Este artigo está estruturado em oito seções, incluindo essa introdução, onde foi feita uma breve explanação sobre o tema proposto além de ser apresentada a motivação que levou a realização deste trabalho e o objetivo central do mesmo. Na segunda seção será apresentada a evolução histórica do setor elétrico brasileiro. A terceira seção apresenta o mercado brasileiro de energia livre e seus aspectos. Na seção quatro será abordada a indústria de shopping centers no Brasil. A seção cinco apresenta os procedimentos metodológicos utilizados no 
artigo. A seção seis apresenta o estudo de caso e a empresa pesquisada. Na seção sete são apresentados os resultados e conclusões e, por fim, a seção oito apresenta as considerações finais, as limitações e recomendações para a realização de futuras pesquisas.

\section{A Evolução Histórica do setor Elétrico e singularidades da Indústria Elétrica}

O histórico do setor elétrico tem como principal marco a descoberta da luz elétrica incandescente, invenção do norte americano Thomas Edison em meados de 1878. Edison revolucionou o modo de vida das gerações seguintes desenvolvendo sistemas que tornaram a luz prática, segura e econômica. Foi por meio dele que a chamada Revolução Industrial ganhou novo impulso (CHINAN, NASSA, 2014).

Em boa parte das atividades realizadas, pelo comércio, indústria e prestação de serviços, a energia elétrica está presente, tornando um insumo essencial e vital para o desenvolvimento econômico e social (GENERGIA, 2016). De acordo com Lee (2004, apud Oliveira, 2017) a eletricidade possui singularidades peculiares, que a difere das demais mercadorias, por desempenhar uma importância crucial na manutenção das rotinas diárias ao bem-estar da sociedade.

Segundo Schor (2018), a indústria de energia elétrica é composta por quatro atividades essenciais: geração, transmissão, distribuição e comercialização. De acordo com Mayo (2012, apud Oliveira, 2017), a comercialização nos mercados de eletricidade é distinta das outras commodities, levando em consideração que é um insumo que não pode ser estocado, e no qual a disponibilidade deve ser instantânea e absoluta.

A economia atual é movida pela energia elétrica e dela as empresas dependem para produção, comercialização e distribuição de seus produtos. Esse insumo fundamental a vida tornou-se a força motriz que movimenta as economias e cria produtos competitivos no mundo globalizado (CHINAN, NASSA, 2014).

De acordo com Tolmasquim (2015, p.12) “A sustentabilidade econômica de um país se fundamenta na capacidade de fornecer logística e energia que atenda a necessidade produtiva com segurança, em condições competitivas, além de ambientalmente sustentável".

O tópico a seguir descreve os principais fatos históricos do setor elétrico brasileiro que passou por grandes mudanças nas últimas décadas. 


\section{Os principais fatos históricos do Setor Elétrico Brasileiro}

Segundo Oliveira (2017), o início do novo modelo do setor elétrico pode ser melhor compreendido sob uma perspectiva histórica, iniciando em 1930 com a crise energética. Destacando fatos como:

- Domínio estatal do setor elétrico entre 1930 e 1990;

- A abertura do setor elétrico a inciativa privada em razão da crise financeiro do setor em 1990;

- A necessidade de reforma do setor, dando início a transição entre o modelo estatal e o que lhe sucedeu;

- O fracasso da reforma de 1990, resultou a crise de abastecimento de 2001. (OLIVEIRA, 2017 p. 14)

O marco na regulamentação do setor elétrico brasileiro foi o Código de Águas, instituído pelo Decreto n 24.643 de 1934, durante o Governo de Getúlio Vargas, que atribuiu ao poder público a possibilidade de controlar as concessionárias de energia elétrica, formalizando assim, o início da intervenção estatal no setor (OLIVEIRA, 2017).

O Modelo Estatal, [...] a indústria elétrica era explorada, majoritariamente por empresas privadas estrangeiras [...], com isso passou a ser marcado por forte domínio estatal, quando a união passou a ter o domínio sobre a construção das usinas e o sistema de distribuição. (TOLMASQUIM, 2015, p.3)

Na Reforma dos anos 1990, de acordo com Tolmasquim (2015, p.5):

O modelo de monopólio estatal prevaleceu até o começo da década e foi responsável pela expansão e a consolidação da indústria elétrica brasileira. Portanto graças a diversas mudanças ocorridas nos anos anteriores e a crise econômica, o modelo se mostrou ineficiente, frente as novas demandas econômicas e sociais.

Ainda na década de 1990 teve início a restruturação do estado, com viés liberal tendo compatibilidade com a nova ordem constitucional econômica, baseando-se em três princípios os quais são eles: desestatização, desverticalização e eficientização, com a intenção de atrair o investimento privado por meio de regime jurídico de concessões (SCHOR, 2018).

Isso marcou a criação de um novo modelo institucional para o setor elétrico, que foi resultado da revisão setorial pelo projeto de reestruturação do setor elétrico. Segundo Araújo (2001 apud Oliveira, 2017), o projeto concluiu que era necessária a modernização do setor, através da introdução da concorrência e de uma estrutura de mercado. Visava a privatização 
das empresas estatais e a desverticalização do setor separando as atividades de geração, transmissão, distribuição e comercialização.

\section{Reforma do Setor elétrico}

O modelo estatal se mostrou insustentável e ineficiente frente as novas demandas econômicas e sociais, surgindo a necessidade da implantação de um regime de mercado competitivo, objetivando aumentar a eficiência das empresas de energia elétrica (TOLMASQUIM, 2015).

Segundo Vasconcellos e Garcia (2005, p.25):

[...] a concorrência perfeita gera um mercado sem falhas, onde o sistema de preços, permite a extração da quantidade adequada de bens e serviços úteis de todos os recursos disponíveis na sociedade, levando a economia a uma eficiente alocação dos recursos $[\ldots]$.

Ainda segundo os autores, "o estado não deveria intervir no funcionamento dos mercados, pois estes resolveriam livremente seus problemas econômicos". (VASCONCELLOS \& GARCIA, 2005, p.26).

O suprimento de eletricidade entrou em um estado de escassez, devido a capacidade não ter crescido em paralelo a demanda de energia elétrica, ainda com a contribuição dos fatores climáticos como a baixa quantidade de chuva em 2001. O racionamento foi declarado e teve fim apenas em 2002 no mandato do governo Fernando Henrique Cardoso, deixando claro os problemas na modelagem do setor elétrico. (ARAUJO, 2001 apud OLIVEIRA, 2017). Segundo Kelman (2001 apud Oliveira, 2017), as razões para as causas do racionamento foram a combinação de três fatores: o primeiro foi dois anos subsequentes desfavoráveis hidrologicamente; a segunda foi a falta de investimentos e atrasos em obras de infraestrutura; e o terceiro e não menos importante, a falta de coordenação e ausência de regulamentos a respeito da responsabilidade das entidades para a gestão de risco de desabastecimento do setor elétrico brasileiro.

Em respostas a essas falhas de mercado, normas jurídicas possibilitaram que a atuação do governo na economia fosse cada vez mais abrangente. Pouco a pouco, a sociedade foi vivenciando a mão visível do governo, como forma de aumentar a eficiência econômica. Sua atuação se faz por meio de leis, as chamadas leis de 
defesa da concorrência, que regulam tanto as estruturas de mercado, como a conduta das empresas. (VASCONCELLOS; GARCIA, 2005 p.27).

O novo modelo foi concebido depois de uma série de reformas estruturantes, o que ocasionou mudanças no setor elétrico que conduziram a implementação do modelo atual.

\section{Primeiras Modificações do setor elétrico nacional}

A indústria da eletricidade nacional passou por diversas mudanças para a organização das suas atividades.

Em meados de 1995 o Estado mudou as bases estruturantes do setor elétrico, instituindo um novo modelo, sendo guiado por uma consultoria internacional e com financiamento do Banco Mundial (SCHOR, 2018). Havia uma verticalização onde todo o processo de geração e distribuição era realizado apenas por empresas estatais (RIZKALLA, 2018).

O setor elétrico nacional desenvolveu-se sob domínio do capital privado, especialmente estrangeiro, sem qualquer regulação para tais atividades, e a sua exploração era acondicionada a aprovação apenas dos municípios (TOLMASQUIM, 2015)

Incentivado pela onda de privatizações em diversos países e impelido pela necessidade de aumentar a arrecadação, o Governo Federal deu partida no processo de privatização das empresas de energia elétrica nacional, antes mesmo de estar definido o novo marco regulatório setorial (SCHOR, 2018)

Para essa reforma, baseou-se um consenso no qual deveria organizar e direcionar as políticas de desenvolvimento do setor, além de regulá-lo.

\section{Principais instituições atuantes no setor elétrico brasileiro}

A estrutura hierárquica do Sistema Elétrico Brasileiro é composta por diversos agentes com atribuições e objetivos diferentes. No modelo vigente essas instituições agem para a regulamentação do mesmo. Serão explicados os principais papeis de cada uma dessas instituições. 
Figura 1 - Atual estrutura do setor elétrico brasileiro e como os órgãos se relacionam entre si

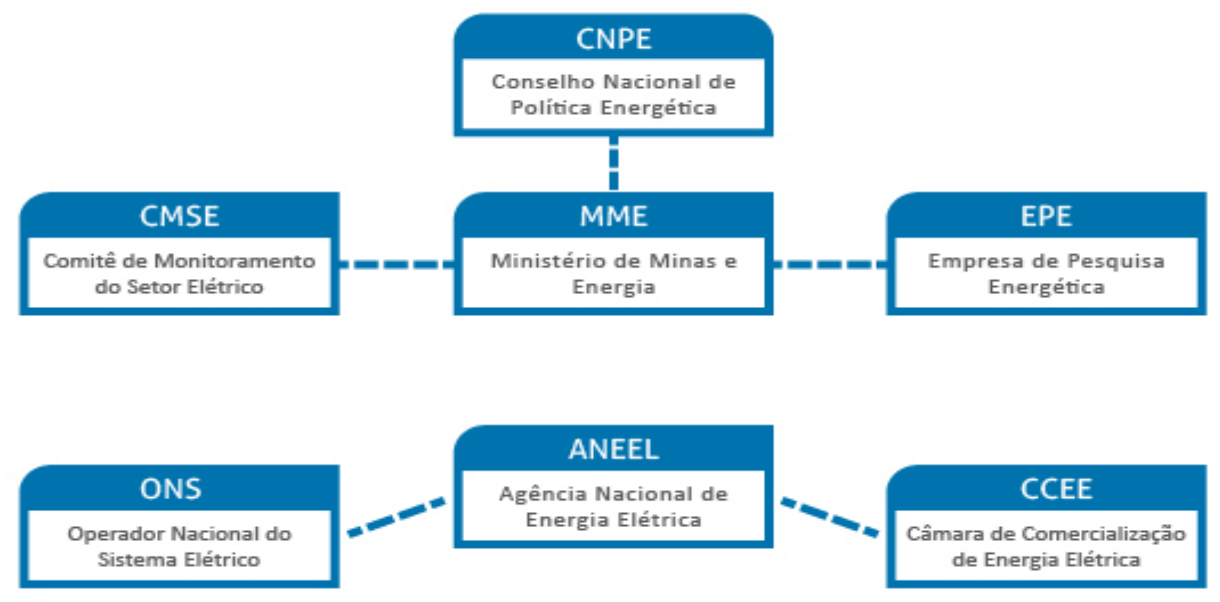

Fonte: CCEE 2017

O governo federal é responsável pelo comando e fixação de objetivos do estado e manutenção da ordem jurídica. Partindo desse princípio do setor elétrico tem algumas instituições que desempenham tais papeis. As atividades dessa indústria organizam-se em cadeia, de acordo com as atribuições indispensáveis a manutenção do setor: da geração a transmissão, e ao final, distribuição (SCHOR, 2018).

O CNPE (Conselho Nacional de Políticas Energética), foi criado pela lei 9.478/97 regulamentado pelo decreto 3.520/2000, é um órgão do governo que é vinculado à presidência da república, tem como presidente o Ministro de Minas e Energia. Sua principal competência é propor políticas e diretrizes que se relacionam com o Setor Elétrico Brasileiro, tem como responsabilidade promover o aproveitamento dos recursos energéticos de forma racional, assegurar o suprimento de insumos energéticos as áreas de difícil acesso, rever periodicamente as matrizes energéticas de todas as regiões do país, estabelecer diretrizes para programas específicos, como por exemplo o uso de gás natural, estabelecer diretrizes para importação e exportação, além de sugerir a adoção de medidas necessárias para garantir o atendimento a demanda nacional de energia elétrica, considerando o planejamento de longo, médio e curto prazo (TOLMASQUIM, 2015)

O CNPE tem como função dar estabilidade regulatória e jurídica, garantindo a plena aplicação das regras e regulamentos que balizam o funcionamento do mercado, com respeito aos contratos, e previsibilidade, priorizando a publicidade para que os investidores e a 
economia possam se preparar para responder às oportunidades, em conjunto com a Empresa de pesquisa Energética (EPE) (TOLMASQUIM,2015)

A Empresa de Pesquisa Energética- EPE, tem por principal finalidade fazer estudos e pesquisas a subsidiar e dar apoio técnico a planejamento do setor elétrico (TOLMASQUIM, 2015)

\footnotetext{
Realiza estudo e projeções da matriz energética brasileira;

Elabora e publica o balanço energético nacional;

Identifica e quantifica o potencial dos recursos energéticos;

Dá suporte e participa de articulações para aproveitamento dos rios que são compartilhados com os países vizinhos;

Realiza estudo para determinar o aproveitamento eficaz dos potenciais hidráulicos;

Obtém a licença prévia ambiental e a declaração de disponibilidade hídrica, que são necessárias para licitações de empreendimentos hidrelétricos e de transmissão;

Elabora os estudos necessários para desenvolvimento dos planos de expansão de geração e transmissão de energia em curto, médio e longo prazo. (TOLMASQUIM, 2015 p.34)
}

Os estudos servem como suporte para que o Ministério de Minas e Energia, possa implementar a política energética adotada pelo CNPE (TOLMASQUIM, 2015). O MME (Ministério de Minas e Energia) é o órgão responsável pela formulação e implantação de políticas no setor de energia, criado pela lei 3782/1960, e definido pela lei 10683/2003, como de competência as áreas de geologia aproveitamento de energia hidráulica petróleo combustível energia elétrica; recursos minerais e energéticos; mineração e metalurgia, incluindo a nuclear (TOLMASQUIM, 2015).

As instituições se relacionam entre si como instituições responsáveis pelo equilíbrio operacional do mercado de comercialização de energia, a Câmera de Comercialização de Energia Elétrica - CCEE atua sempre em sintonia com as demais instituições do setor elétrico brasileiro.

\section{Modalidades de Agentes}

Os agentes da Câmara de Comercialização de Energia Elétrica são empresas que atuam no setor de energia elétrica nas áreas de geração, distribuição e comercialização. Há ainda os consumidores livres e consumidores especiais, conceitos associados à demanda e também à fonte de geração de energia (CCEE, 2017) 
Além dos órgãos institucionais apresentados a indústria da eletricidade é composta por vários seguimentos que são organizados de forma a proporcionar o correto funcionamento do setor. Ao final dessa cadeia produtiva estão os usuários de energia que, por sua vez se classificam, em diversos grupos dependendo do tamanho da sua carga e de quem adquirem sua energia (SCHOR, 2018)

Figura 2 - Cadeia Produtiva da Energia Elétrica Brasileira

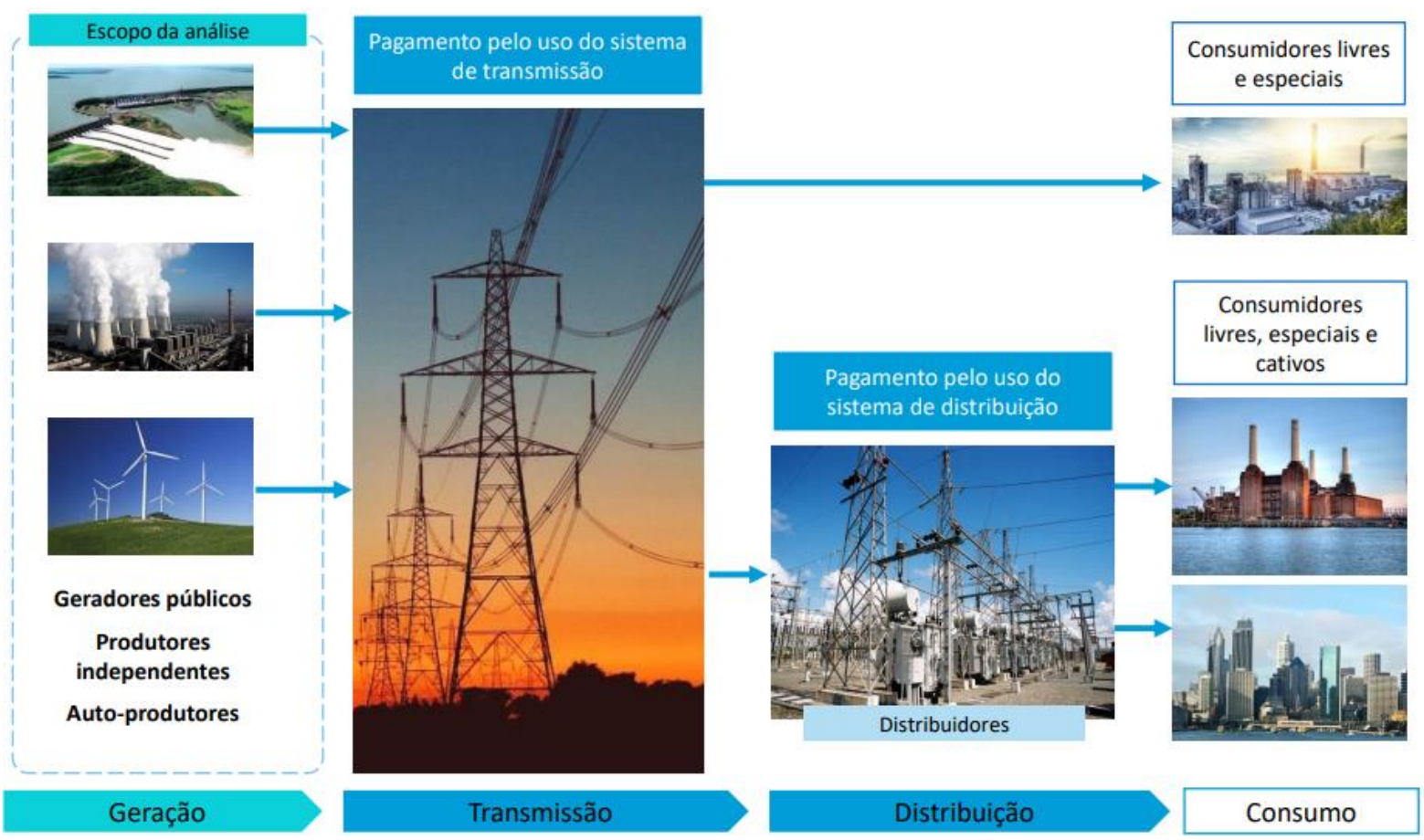

Fonte: ANEEL 2017

Segundo Tolmasquim (2015, p.51) "os agentes econômicos, compostos pelos consumidores de energia e os agentes que são titulares das concessões para a exploração das atividades de geração, transmissão, distribuição e comercialização".

O modelo dos anos de 1990 institui o acesso livre das instalações de transmissão e distribuição aos consumidores livres e produtores independentes. Dessa forma foi exigido dos concessionários de transmissão e distribuição o compartilhamento de sua infraestrutura, dando permissão ao acesso à rede. Essa obrigação foi mantida e é operacionalizada através de contratos (TOLMASQUIM, 2015). 
O novo modelo contribuiu, portanto, para aperfeiçoar o papel da distribuidora. A realização de leiloes para adquirir energia no Ambiente de Contratação Regulada propicia a modicidade tarifaria; a obrigatoriedade da declaração de demanda assegura o suprimento; e a neutralidade no rapasse de custos não gerenciáveis beneficia o agente distribuidor e consumidor final. (...). (TOLMASQUIM, 2015).

A ideia de um ambiente competitivo no setor elétrico surge da possibilidade de separar o produto do serviço. Os comercializadores de energia elétrica compram a energia através dos contratos bilaterais, podem vender para consumidores livres e especiais, no Ambiente de Contratação Regulada - ACR e Ambiente de Contratação Livre - ACL (SCHOR, 2018).

\section{Tipos de Consumidores}

Segundo ABRACEEL (2017), na atual conjuntura do mercado brasileiro de energia elétrica existem três tipos de consumidores, relacionados a seguir.

Consumidor Cativo - são consumidores do Ambiente de Contratação Regulada. Não têm a liberdade de optar pelo seu fornecedor, estão condicionados ao pagamento da tarifa de energia que é determinada pela ANEEL. Neste caso os consumidores recebem o fornecimento de contratuais, ou seja, os usuários cativos têm a conjugação obrigatória das atividades de transporte e comercialização da energia pelo agente de distribuição (DURANTE, 2016)

Consumidor Livre - são consumidores que têm livre escolha para contratação do seu fornecedor de energia elétrica sendo gerador ou comercializador e podendo negociar preços e condições contratuais, que possuem demanda contratual igual ou superior a $3.000 \mathrm{~kW}$ e tensão mínima de $69 \mathrm{kV}$ (kiloVolt). Novos consumidores com carga superior a $3.000 \mathrm{~kW}$ (kiiloWatt), conectados ao Sistema Interligado Nacional, após 7 de julho de 1995, não estão sujeitos ao limite de tensão (TOLMASQUIM, 2018)

Consumidor Especial - recebe esta qualificação o consumidor com demanda superior a $500 \mathrm{~kW}$ e inferior a $3.000 \mathrm{~kW}$ e que sejam atendidos a tensão maior ou igual a 2,3 kV, estes podem contratar apenas de fontes incentivadas, nesse caso não há desconto na tarifa de usos da rede de transmissão e distribuição. Nesse caso o fornecimento pode ser complementado por qualquer outro empreendimento de geração que se associe às fontes não especiais a fim de apuração de desconto e do mercado de curto prazo, porém ao limite de $49 \%$ da energia produzida (TOLMASQUIM, 2015). 


\section{Modalidade de estrutura tarifaria}

O Brasil é o sétimo pais no mundo com maior custo para produção de energia elétrica no mundo, no gráfico abaixo mostra que a tarifa medias de Energia Elétrica em 2014 para a Industria e Comercio, com base nas tarifas praticadas pela ANEEL (EPE, 2017)

São estabelecidos dois períodos para as horas do dia, classificados postos tarifários. O posto tarifário "ponta" é correspondente ao horário de maior consumo, que geralmente ocorre entre 18:00h e 21:00h. O posto tarifário "fora de ponta", engloba as demais horas dos dias uteis e as 24:00h dos finais de semana (sábado e domingo) e feriados (OLIVEIRA, 2018).

De acordo com a ANEEL (2017) nos dias uteis, o valor da Tarifa Branca, que é o mecanismo para precificar a energia, irá se dividir em três horários:

- $\quad$ Ponta (das $18 \mathrm{~h}$ às $21 \mathrm{~h})=$ Energia bem mais cara;

- $\quad$ Intermediário (das $17 \mathrm{~h}$ às $18 \mathrm{~h}$ e das $21 \mathrm{~h}$ a $22 \mathrm{~h}$ ) = Energia mais cara;

- $\quad$ Fora de ponta (das $22 \mathrm{~h}$ às $17 \mathrm{~h})=$ Energia mais barata.

Gráfico 1 - Representação dos valores da energia em horários de ponta, intermediário e fora de ponta

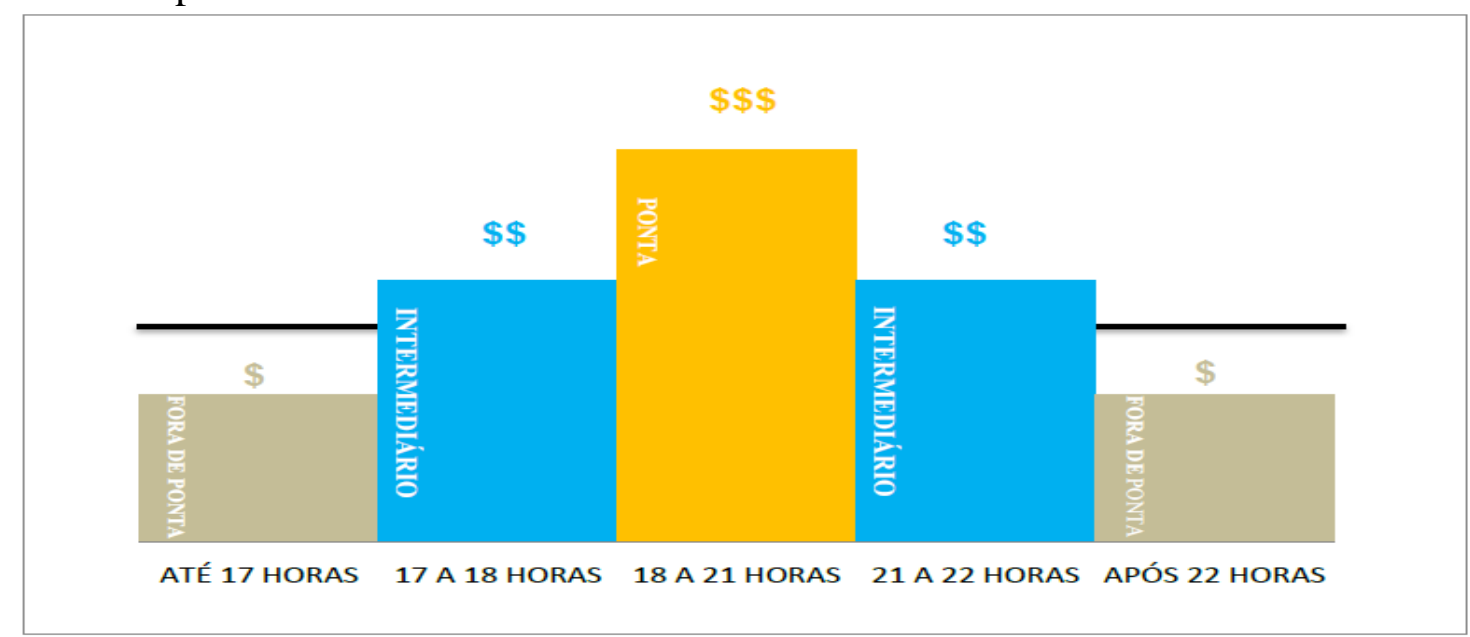

Fonte: ANEEL 2017

Nos feriados nacionais e finais de semana o valor para todas as horas do dia é considerado fora de ponta. Os períodos: Horário de Ponta, Intermediário e Fora de Ponta são homologados pela ANEEL nas revisões tarifarias periódicas de cada distribuidora, que ocorre, em média, a cada 4 anos. 
"A partir de 2015, as contas de energia passaram a utilizar o Sistema de Bandeiras Tarifarias, que indicam se a energia custa mais ou menos, em função das condições de geração de eletricidade" (ANEEL, 2017, p.18).

\footnotetext{
O sistema é dividido em três cores de bandeira: Verde, amarela e vermelha. Bandeira Verde: A tarifa não sofre acréscimo, pois as condições de energia estão favoráveis.

Bandeira Amarela: A tarifa sofre um acréscimo de $\mathrm{R} \$ 0,01$ a cada $\mathrm{kWh}$ consumido. Bandeira Vermelha (Patamar 1): A tarifa sofre acréscimo R $\$ 0,03 \mathrm{kWh}$. Bandeira vermelha (Patamar 2): As condições de geração de energia, são de alto custo e a tarifa sofre acréscimo de $\mathrm{R} \$ 0,05 \mathrm{kWh}$.

As tarifas são definidas considerando a bandeira verde. Se a situação for adversa, podem ser acionadas as bandeiras amarela e vermelha. Se a situação melhora, abandeira pode voltar a ficar verde e, automaticamente, o consumidor tem redução da conta. (ANNEEL, 2016, p.18)
}

"O sistema de bandeiras é aplicado em todos os estados do Brasil, exceto o de Roraima, que ainda não está no Sistema Interligado Nacional” (ANEEL,2017, p.19).

\section{O Mercado Brasileiro de Energia Livre e seus aspectos}

O mercado livre de energia é o ambiente de comercialização onde os agentes podem negociar de forma livre os seus contratos estabelecendo suas condições como, período de fornecimento, preço, volume assim por diante, ao contrário do ambiente regulado onde não há liberdade de negociação entre os agentes (TOLMASQUIM, 2015).

Além da vantagem de livre negociação, o mercado livre de energia oferece outros benefícios como, escolha, competitividade, flexibilidade e previsibilidade tanto de consumo como de custos, que são consequências contratuais.(ABRACEEL, 2017).

Nesse capítulo serão abordadas as particularidades as vantagens do mercado livre, os contratos que regem, métodos de adesão e sobre os perigos no Ambiente de contratação Livre de Energia. 


\section{As vantagens do mercado livre}

O Mercado Livre é uma esfera de contratação de energia que propicia uma significativa economia nos custos, oferecendo espaço para consumidor livre adquirir energia de forma alternativa ao abastecimento das concessionárias locais. Buscando melhores preços e maior previsibilidade nos negócios, empresas como industrias, shopping centers, hospitais e universidades estão migrando para o mercado livre (GENERGIA, 2016).

Em torno de 700 consumidores industriais e comerciais estão migrando para o ambiente de contratação livre, implicando em um aumento beirando a $40 \%$ na quantidade de clientes já existentes no seguimento, o ambiente livre é responsável pelo consumo de $25 \%$ da energia no Brasil, pelos cálculos do relatório anual da ANEEL cerca de 14 mil consumidores preenchem os requisitos para migrar para esse mercado (GENERGIA, 2016).

As principais vantagens do mercado livre brasileiro são;

Maior previsibilidade orçamentaria;

Alocação de energia para empresas do mesmo grupo;

Preço mais competitivos do que no mercado cativo;

Possibilidade de adequação da compra de energia ao processo produtivo;

Mesmos preços para os horários de ponta e fora de ponta. (GENERGIA, 2016, p.4)

Essas vantagens somadas ao período de instabilidade econômico-política em que o país atravessa, fizeram do mercado livre a melhor opção de redução de custos e de melhora da previsibilidade orçamentária, sendo que a maior parte dos contratos negociados tem prazo igual ou superior a quatro anos, como será abordado no próximo tópico.

\section{A Industria de Shopping Centers no Brasil}

Segundo o Internacional Council of Shopping Centers (ICSC, 2003 apud (GOMES; PORTUGUAL e BARROS, 2004, p.283),

\footnotetext{
Shopping center é definido como um grupo de estabelecimentos comerciais unificados arquitetonicamente e construído em terreno previamente planejado e desenvolvido. Deverá ser administrado como uma unidade operacional, sendo o tamanho e o tipo de lojas existentes relacionadas diretamente com a área de influência comercial a que essa unidade serve. Deverá também oferecer estacionamento compatível com todas as lojas existente no projeto.
} 
De acordo com a Associação Brasileira de Shopping Centers - ABRASCE, é o local onde as pessoas buscam satisfazer seus desejos como consumo lazer e interação social em um ambiente onde consumidores e comerciantes interagem de forma integrada. Os Shoppings Centers devem ter algumas características tais como, ter lojas com mix diversificados de produtos e serviços, os locatários estejam sujeitos a padrões contratuais para garantir a manutenção do equilíbrio da convivência integrada e que haja variação do preço da locação, de acordo com o faturamento dos locatários. (ABRASCE, 2003 apud GOMES; PORTUGUAL \& BARROS, 2004).

A indústria de shopping centers tem sua importância pela sua significativa contribuição para gerar empregos. No país em 2018, foram gerados 1.085 .040 empregos para atender as demandas crescente dos shoppings. Além disso, a indústria de shopping centers brasileira tem contribuído para a geração de renda com faturamento médio em 2018 de 178,7 bilhões de reais (ABRASCE, 2018).

Os shoppings contribuem também com o desenvolvimento urbano já que tendem a modernizar a área na qual se localiza, assim como produz um grande aumento de serviços, mercadorias e consumidores, que valorizam a região na qual está instalada (PORTUGAL; GOLDER, 2003).

No Brasil o setor de shoppings centers encontra-se em um processo de desenvolvimento acelerado, constante e solido. Através da profissionalização e amadurecimento contando ainda com investimentos nacionais e internacionais (ABRASCE, 2018).

\section{Principais receitas e despesas na administração de um shopping center}

As principais receitas e despesas existentes na administração de um shopping center são provenientes principalmente da locação dos seus espaços, dando origem ao aluguel, condomínio e fundo de promoção (ABRASCE, 2018). Esta pesquisa irá se aprofundar nos custos condominiais pois é em busca da redução do mesmo que a presente pesquisa foi elaborada. 


\section{Condomínios}

O condomínio pode ser definido de acordo com Moura (2005, apud Júnior et. al, 2009), como uma propriedade que pertence a mais de uma pessoa ao mesmo tempo, e todas elas têm direito e deveres iguais sobre cada uma das partes e sobre o todo. Esse percentual é destinado a administração das áreas comuns entre o empreendedor o varejista e o consumidor.

\section{Procedimentos Metodológicos}

A presente pesquisa tem como objetivo principal analisar a viabilidade financeira da migração de um consumidor empresarial do mercado cativo para o mercado de energia elétrica livre, sob a ótica da gestão eficiente dos recursos financeiros. Para isso realizou-se de um estudo de caso sobre a migração para o mercado livre de energia de um consumidor que pertenceu ao mercado cativo, analisando as características e adequações necessárias a migração e a viabilidade econômico-financeira, sob a ótica financeira na gestão de custos e análise da influência dos custos operacionais.

Quanto aos objetivos trata-se de pesquisa exploratória e bibliográfica. Segundo Gil (2002), objetiva propiciar familiaridade com o problema estudado, para torná-lo mais explícito. O método de estudo de caso, segundo Vergara (1990, p.44) “[...] tem caráter de profundidade e detalhamento. [...] e, utiliza métodos diferenciados de coleta de dados".

De acordo com Lakatos; Marconi (1995, p.106), quanto ao método de abordagem é o hipotético-dedutivo. Quanto o meio de análise dos dados é quantitativo, segundo Raupp e Beuren (2006, p.92), A abordagem quantitativa caracteriza-se pelo emprego de instrumentos estatísticos, tanto na coleta quanto no tratamento dos dados.

\section{Verificação da viabilidade econômica}

Para a presente pesquisa será utilizado o método de análise conhecido como ponto de equilíbrio, que determina o valor de um parâmetro ou variável de decisão que faz com que duas relações sejam iguais (TARQUIN, 2008). 
Quanto aplicado a tarifa de energia elétrica é possível entender o ponto de equilíbrio como o valor máximo, em unidades monetárias que pode ser levado em consideração, para permitir que a opção de compra da energia elétrica, seja neutra, tanto no mercado regulado quanto no livre. Ou seja, ao usar esse método é possível encontrar o preço da energia onde não há diferenças entre a contratação regulada e contratação livre, sob o ponto de vista econômico (GENERGIA, 2017).

\section{Estudo de Caso}

\section{Caracterização do objeto de empresa pesquisada}

O Shopping Center pesquisado está localizado no estado do Maranhão, situado em uma área de influência de grandes projetos, sendo líder de um importante polo econômico, que responde fortemente pela economia regional. Possui área total terreno $42.000 \mathrm{~m}^{2}$, área total construída 53.379,07 m²; Área Bruta Locável 27.970 m², contendo 184 lojas, 15 âncoras e mega lojas, 5 salas de cinema, 28 operações de alimentação e 1.300 vagas de estacionamento, uma agência bancaria. Com variação de fluxo de pessoas de 350 a 600 mil por mês.

O consumidor em questão era atendido pela concessionaria de energia CEMAR (Companhia Energética do Maranhão), com tensão de fornecimento $69 \mathrm{kV}$. Seu contrato vigente se encontrava na modalidade tarifaria horo sazonal amarela sendo a demanda contratada de $1.050 \mathrm{~kW}$. Contratava energia no Ambiente de Contratação Regulada, mesmo possuindo demanda necessária para a migração ao Ambiente de Contratação Livre, em março 2017 iniciou o processo para avaliação de migração de mercado livre de energia.

\section{A composição dos custos condominiais do shopping center pesquisado}

De acordo com a Administradora do Shopping Center as principais receitas presentes no processo de administração do shopping decorrem da cobrança do condomínio, aluguel e fundo de promoção, podendo haver outros faturamentos como, taxa de cessão de direitos: os lojistas pagam pelo direito de utilizar os espaços comerciais no shopping, os valores são 
negociados de acordo com o valor de mercado dos pontos observando que quanto mais produtivo for o shopping mais elevados são os valores; taxa de transferência, é cobrada um percentual quando ocorre o repasse de uma loja para um novo lojista; estacionamento em boa parte dos empreendimento há cobrança de uma taxa horaria oriunda da utilização dos espaços de estacionamento de veículos; quiosques ou ilhas é o aluguel para utilização de espaço nos corredores do estabelecimento, com contratos de geralmente 6 meses, podendo ser renovados e merchandising; valor cobrado para divulgação dos espaços comuns do shopping center.

O valor da taxa condominial que deve ser paga pelos varejistas é definido pelo um cálculo de percentual sobre o total das despesas comuns afirma a administradora. A Administradora do shopping center, utiliza-se de duas formas de cobrança do valor condominial: pro rata com base na área das suas lojas e taxas fixas os lojista pagam a mesma taxa sem considerar tamanho das lojas.

$\mathrm{Na}$ figura abaixo mostra a composição dos custos condominiais referente ao exercício Dezembro/2016, custos esses que são rateados entre lojistas e empreendedor pois nesse período haviam lojas vagas. Os dados para a montagem das informações foram fornecidos pela administração do empreendimento.

Quadro 1 - Rateio dos Custos Condominiais

\begin{tabular}{|c|c|c|}
\hline \multicolumn{3}{|c|}{ Encargos condominiais - Dezembro - 2016} \\
\hline Encargos Comuns & dez/16 & $\begin{array}{c}\% \text { de participação } \\
\text { nas despesas }\end{array}$ \\
\hline Total dos encargos comuns & $676.499,77$ & \\
\hline $\begin{array}{l}\text { Taxa Administrativa } \\
\text { Contribuição - Empreendedor }\end{array}$ & $\begin{array}{l}37.380,00 \\
50.000,00\end{array}$ & \\
\hline Totais do encargos comuns + Taxa Adm - Contribuição do Empreendedor & $663.879,77$ & \\
\hline Despesas Operacionais & $713.879,77$ & \\
\hline Salarios e Beneficios & $407.976,20$ & $61,45 \%$ \\
\hline Material de uso e administração & $26.579,00$ & $4,00 \%$ \\
\hline Material de Limpeza & $7.080,00$ & $1,07 \%$ \\
\hline Telefonia+Internet & $8.428,90$ & $1,27 \%$ \\
\hline Contratos fixos & $66.049,00$ & $9,95 \%$ \\
\hline Tarifas Públicas_e_Bancárias & $3,021,00$ & $0,46 \%$ \\
\hline Insumos Energéticos & $154.565,67$ & $23,28 \%$ \\
\hline Energia elétrica comum & $121.017,38$ & \\
\hline Energia elétrica - estação de tratamento água e esgoto & $3.548,29$ & \\
\hline Combustivel - Gerador & $30.000,00$ & \\
\hline Serviços Publicos & $2.800,00$ & $0,42 \%$ \\
\hline Taxa Administrativa & $37.380,00$ & $5,63 \%$ \\
\hline
\end{tabular}

Fonte: Empresa estudada Elaborado pelos autores/2019 
O insumo energético é o segundo no Ranking das despesas condominiais ficando atrás apenas dos custos com salários e benefícios. Em meados de março de 2017 deu-se início o estudo de viabilidade de migração para o Mercado Livre de Energia.

\section{Análise dos insumos energéticos}

O fornecimento de energia é trifásico, decorrente da rede aérea disponibilizado pela concessionária de energia, (Companhia Energética do Maranhão) - CEMAR, e conectada a subestação aérea por meio do circuito de distribuição em tensão primária ao transformador.

Durante a caracterização dos sistemas, observou-se que eram utilizadas as seguintes fontes de energias primarias para alimentar as principais operações do shopping:

Energia elétrica; Óleo Diesel.

No quadro a seguir são apresentados os dados de fornecimento de energia elétrica da unidade operacional tendo como mês de referência o mês de Dezembro/2016.

Tabela 1 - Consumo da unidade operacional

\begin{tabular}{|c|c|c|c|c|c|}
\hline ITEM & DESCRIÇÃO & TIPO & CONTRATADO E FATURADO & TARIFAS R $\$$ & TOTAL R $\$$ \\
\hline 1 & Demanda & & $1050 \mathrm{~kW}$ & 17,99 & $18.889,50$ \\
\hline 2 & Consumo Médio Fora de Ponta & TUSD & $270.841 \mathrm{kWh}$ & 0,0436 & $11.808,66$ \\
\hline 3 & Consumo Médio Ponta & TUSD & 717 kWh & 1,3487 & 967,01 \\
\hline 4 & Consumo Médio Fora de Ponta & TE & $270.841 \mathrm{kWh}$ & 0,20496 & $55.511,57$ \\
\hline 5 & Consumo Médio Ponta & TE & 717 kWh & 0,31648 & 226,92 \\
\hline 6 & Adiconal de Bandeira Amarela & & $271.558 \mathrm{kWh}$ & 0,01500 & $4.073,37$ \\
\hline 7 & \multicolumn{4}{|c|}{ SUBTOTAL (Item $7=1+2+3+4+5+6$ ) } & $91.477,03$ \\
\hline 8 & \multicolumn{4}{|c|}{ ICMS (26\%) } & $24.203,48$ \\
\hline 9 & \multicolumn{4}{|l|}{ PIS/COFINS(6,11\%) } & $5.336,87$ \\
\hline 10 & \multicolumn{4}{|c|}{ VALOR TOTAL DA FATURA DE ENERGIA COM IMPOSTOS (Item $10=7+8+9$ ) } & $121.017,38$ \\
\hline 11 & \multicolumn{4}{|c|}{$\begin{array}{l}\text { PREÇO MÉDIO DA ENERGIA }(\mathrm{R} \$ / \mathrm{MWh}) \\
\text { ITEM } 11=(\text { Valor Total da Fatura R } \$ / \text { Energia Total } \mathrm{KWh}) * 1000\end{array}$} & 445,64 \\
\hline
\end{tabular}

Fonte: Elaborado pelos autores/2019.

$\mathrm{Na}$ análise tarifária da composição do custo da unidade operacional pesquisada, observa-se que o consumo médio na "ponta" é baixo correspondendo apenas $0,26 \%$ do consumo total de $271.558 \mathrm{kWh}$, tendo relação direta com as elevadas tarifas praticadas pelo mercado cativo. 
Tabela 2: Consumo de óleo diesel

\begin{tabular}{|l|c|}
\hline \multicolumn{2}{|c|}{ CONSUMO ÓLEO DIESEL ANO 2016 } \\
\hline Consumo médio de óleo diesel (I/mês) & 12.245 \\
\hline Consumo médio de óleo diesel nos últimos meses (I/ano) & 146.939 \\
\hline Preço médio do óleo diesel (R\$/I) & 2,45 \\
\hline Total em R\$ mês & $30.000,01$ \\
\hline Total em R\$ ano & $360.000,06$ \\
\hline
\end{tabular}

Fonte: Elaborado pelos autores/2019.

Para suprir essa necessidade do consumo na ponta, a unidade operacional pesquisada optou por utilizar a geração de energia térmica através de um gerador alimentado por diesel economizando assim 60,05\% no custo de produção de energia na ponta, saindo de uma tarifa (TUSD E TE) de R \$ 1,66518 (R\$ por kWh) para $\mathrm{R} \$ 1,00(\mathrm{R} \$$ por $\mathrm{kWh})$.

$\mathrm{Na}$ tabela abaixo as duas fontes energéticas são somadas, totalizando o valor total gastos com insumos energéticos, na unidade operacional pesquisada.

Tabela 3: Total do gastos com energia

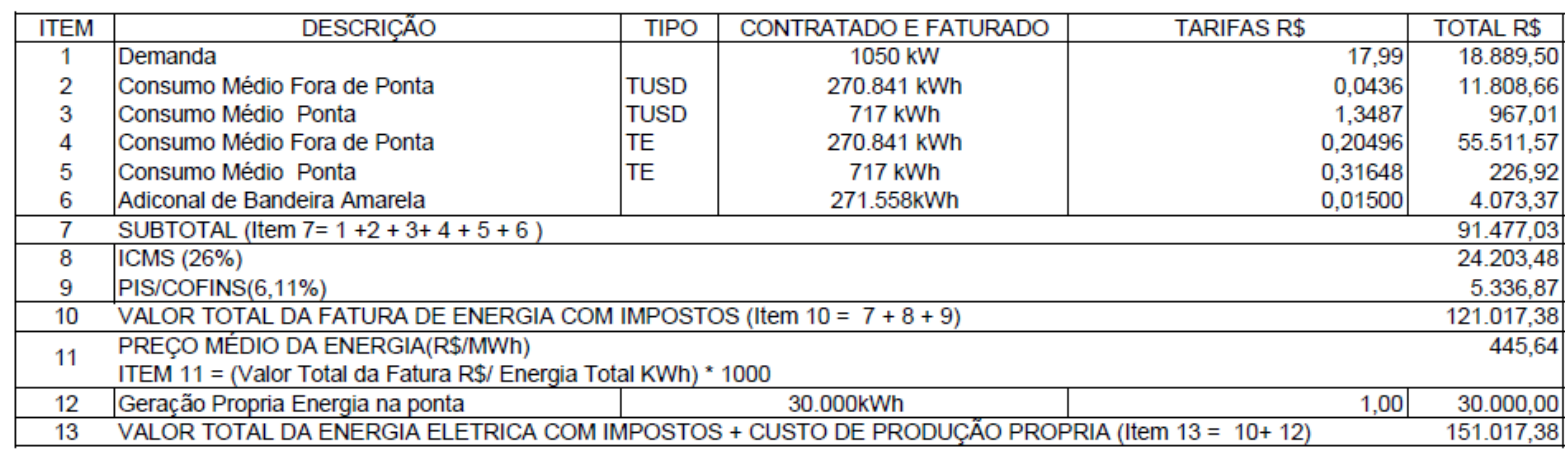

Fonte:. Elaborado pelos autores/2019

Todos os parâmetros utilizados foram retirados do mês de Dezembro de 2016, como consumidor cativo, conforme apresentado na figura. Na sequência para realizar a comparação entre mercado cativo e livre, a Tarifa de Energia (TE) deve ser separada. Para isso utilizar- se uma planilha que apresenta apenas o valor comum aos dois ambientes de contratação que é a Tarifa de Uso do Sistema de Distribuição (TUSD). De acordo com a figura, obteve-se um valor médio da TUSD correspondente a 187,07 R\$/MWh 
Tabela 4: Valor médio da TUSD

\begin{tabular}{|c|c|c|c|c|c|c|c|}
\hline & \multicolumn{7}{|c|}{ USO GERAL DA REDE/CEMAR } \\
\hline ITEM & DESCRIÇAO & TIPO & CONTRATADO E FATURADO & TARIFAS RS S I DESCONTO & $\begin{array}{l}\text { DESCONTO CONSUMIDOR } \\
\text { INCENTIVADO 50\% }\end{array}$ & TARIFAAPLICADA RS & TOTALRS \\
\hline 1 & Demanda & & $1050 \mathrm{~kW}$ & 17,80 & 8,00 & 8,805 & $8.444,75$ \\
\hline 2 & Consumo Médio Fora de Ponta & TUSD & $270.841 \mathrm{kWh}$ & 0,0438 & 0 & 0,0438 & $11.814,08$ \\
\hline 3 & Consumo Médio Ponta & TUSD & $30.717 \mathrm{kWh}$ & 1,4487 & 0,65 & 0,6862 & $21.384,10$ \\
\hline & & & $301558 \mathrm{kWh}$ & & & & \\
\hline 4 & SUBTOTAL (Item $4=1+2+3)$ & & & & & & $42,842,83$ \\
\hline 5 & $\operatorname{ICMS}(28 \%)$ & & & & & & $11.282,80$ \\
\hline 8 & $P I S I C O F \mid N S(6,11 \%)$ & & & & & & $2.487,83$ \\
\hline 7 & VALORTOTAL DAFATURA DE & |IMPOST & $6(\operatorname{tit} 7=4+5+8)$ & & & & $58,413,45$ \\
\hline 8 & $\begin{array}{l}\text { PRECO MEDDIO DA ENERGIAR } \\
\text { TEMM } 8=(\text { Valor Total da Fatura }\end{array}$ & KWh $)^{\prime}$ & & & & & 187,07 \\
\hline
\end{tabular}

Fonte: . Elaborado pelos autores/2019.

A tarifa média total no mercado cativo, separadas em TUSD e TE, o valor da Tarifa de Energia (TE) foi obtido atraves da tarifa média total como consumidor cativo reduzida da tarifa de uso do sistema de distribuição (TUSD). Ao fazer-se a diminuição separa-se o produto energia eletrica da tarifa total e observa-se de maneira objetiva a composição tarifaria resumidamente, o consumidor paga por dois produtos, sendo o primeio o uso do sistema de distribuição da concecionaria e o segundo é o insumo energia eletrica.

Quadro 2 - Separação total da tarifa média total de TUSD e TE

\begin{tabular}{|c|c|c|}
\hline $\begin{array}{l}\text { TARIFA MÉDIA TOTAL } \\
\text { COMO CONSUMIDOR } \\
\text { CATIVO EM R\$/MWh }\end{array}$ & $\begin{array}{l}\text { TUSD MÉDIA TOTAL } \\
\text { COMO CONSUMIDOR } \\
\text { CATIVO EM R\$/MWh }\end{array}$ & $\begin{array}{l}\text { TARIFA DE ENERGIA } \\
\text { "TE" TOTAL COMO } \\
\text { CONSUMIDOR CATIVO } \\
\text { EM R\$/MWh } \\
\end{array}$ \\
\hline 445,00 & 187,07 & 257,93 \\
\hline A & B & $C=A-B$ \\
\hline
\end{tabular}

Fonte: . Elaborado pelos autores/2019

O ponto comum para consumidores dos dois ambientes de contração livre ou regulado, é a remuneração obrigatória pelo uso dos sistemas de distribuição -TUSD. A própria legislação setorial desenhou o sistema elétrico dessa maneira, onde todos os consumidores, sem diferenciação de mercado devem arcar pelos aportes de capital e investimentos feitos 
pelo Estado para construção de linhas de distribuição e outros custos envolvidos. Sendo assim o uso compartilhado por concessionários e seus custos de construção, manutenção e operação divididos entre os usuários.

Então ficando evidente que o comparativo para ser analisado a viabilidade econômica na migração para o mercado livre é restrito a tarifa de energia -TE. Com base ne preços no mercado livre de energia apresentado, na comparação entre a tarifa de energia - TE paga pelo consumidor no mercado cativo na época do estudo (257,93 por MWh) mais a geração própria na ponta $\mathrm{R} \$ 690,00$ por $\mathrm{MWh}$ totalizando $\mathrm{R} \$ 947,93$ por $\mathrm{MWh}$, e o preço para o mercado livre para contratos firmados em março de 2017( 220,60 por MWh mais $\mathrm{R} \$ 187,07$ referente ao TUSD, totalizando $\mathrm{R} \$ 407,67$, a redução no preço de aquisição desse produto estaria na ordem de 43,01\%, o é um ganho expressivo e relevante.

Gráfico 2 - Diferença do preço médio dos insumos energéticos em $\mathrm{R} \$ / \mathrm{MWh}$

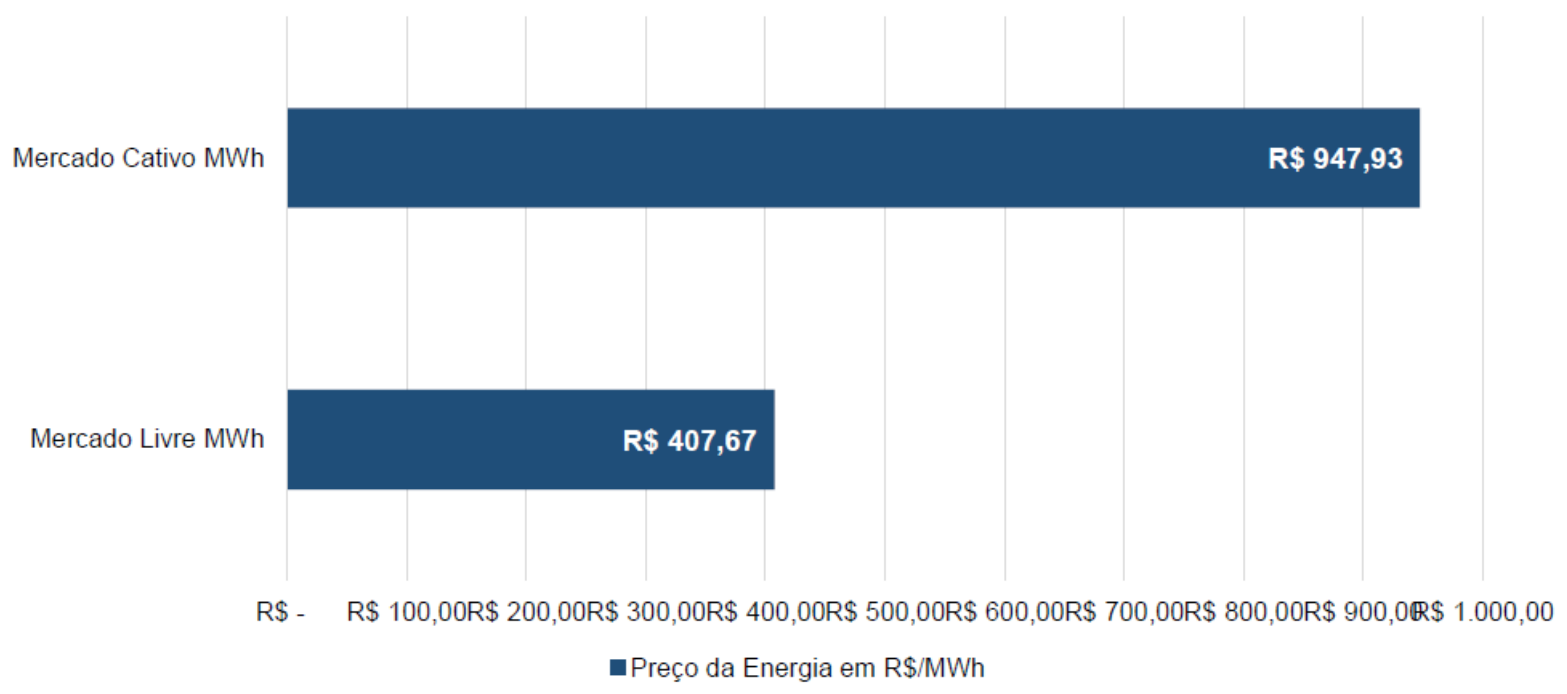

Fonte: elaborado pelos autores/2019. Dados Fornecidos pela unidade operacional pesquisada

Utilizando o método proposto que é o ponto de equilíbrio, observa- se que o valor máximo em Reais, que deve ser levado em consideração para aquisição de energia seja nula em ambos os mercados é R $\$ 947,93$ por MWh, analisando ambas as demandas a atendida pela concessionaria local, e o custo de geração própria no horário de ponta. Com isso tem-se as seguintes observações: 
A tarifa de uso do TUSD é a mesma na condição de consumidor livre ou cativo ou livre, onde os comparativos de viabilidade econômica ficam reservados a tarifa de energia TE.

Para o caso estudado considerar sua migração para o mercado livre, deverá ser observada a contratação de uma tarifa inferior a R \$ 257, 93 por MWh e R \$ 690,00 por MWh que corresponde a geração própria somando as duas totalizando $\mathrm{R} \$ 947,93$ por MWh para toda a demanda necessária.

Para o consumidor analisado nessa pesquisa, observa-se que os objetivos econômicos podem ser obtidos na migração para o mercado livre, partindo de um custo $\mathrm{R} \$ 947,93$ por MWh para R\$ 407,11por MWh.

Neste caso, estipula-se o valor total da energia elétrica necessária para a manutenção da unidade operacional pesquisada, estimando uma economia mensal considerando bandeira tarifaria amarela em $\mathrm{R} \$ 27.879,96 /$ mês e $\mathrm{R} \$ 334.559,52 /$ ano, com 18,46\% de economia final, sobre os gastos com a CEMAR e com a geração própria Energia Térmica, adotando a melhor alternativa de suprimento, energia incentivada com $50 \%$ de desconto sobre a tarifa de demanda que no ambiente regulado era de $\mathrm{R} \$ 17,99$ por $\mathrm{kW}$, com o desconto de $50 \%$ passando para $\mathrm{R} \$ 8,995$ no mercado livre.

A migração para o mercado livre, ainda que com o preço da energia mais barato, requer um investimento para que a migração ocorra, o consumidor teve que adequar seu sistema de medição para o faturamento adequado de acordo com o procedimento de rede do Operador Nacional do Sistema Elétrico - ONS.

Essa adequação custou $\mathrm{R} \$ 25.580,00$ para o sistema de $15 \mathrm{Kv}$. Para a avaliação da viabilidade financeira de migração com o playback de retorno em 27,53 dias. A análise de sensibilidade pelo método do payback simples

$$
\begin{aligned}
\text { Payback }= & \underline{\mathrm{I}_{0}} \\
\mathrm{R}_{\mathrm{t}} & \frac{25.580,00}{27.879,96 / 30}=27,53 \mathrm{dias}
\end{aligned}
$$

Onde;

Payback $=$ o tempo de retorno do investimento, unidade de tempo;

$\mathrm{I}_{0}=\mathrm{o}$ valor inicial do investimento em reais

$\mathrm{R}_{\mathrm{t}}=$ fluxo de caixa líquido no período considerado, em reais / (unidade de tempo) 
Gráfico 3 - Diferença custo de adequação ao sistema de medição e faturamento versus a economia mensal estimada

Economia Mensal Estimada no Mercado Livre

Investimento Adequação Sistema de Medição

Fonte: Elaborado pelos autores/2019

A economia estimada mensal é maior do que o investimento necessário para adequação do sistema de medição, tornando totalmente viável a adequação do mesmo.

Quadro 3 - Comparativo das despesas condominiais de 2016 e 2018

\begin{tabular}{|c|c|c|c|}
\hline Encargos Comuns & $\operatorname{dez} / 16$ & dez/18 & Evolução 2016x2018 \\
\hline Total dos encargos comuns & $521.934,10$ & $629.517,96$ & $20,61 \%$ \\
\hline $\begin{array}{l}\text { Taxa Administrativa } \\
\text { Contribuição - Empreendedor }\end{array}$ & $\begin{array}{l}37.380,00 \\
50.000,00\end{array}$ & $\begin{array}{r}33.344,90 \\
25.000,00\end{array}$ & $\begin{array}{l}-10,79 \% \\
-50,00 \%\end{array}$ \\
\hline Totais do encargos comuns + Taxa Adm - Contribuição do Empreendedor & $509.314,10$ & $637.862,86$ & $25,24 \%$ \\
\hline Despesas Operacionais & $559.314,10$ & $662.862,86$ & $18,51 \%$ \\
\hline Salarios e Beneficios & $407.976,20$ & $397.754,94$ & $-2,51 \%$ \\
\hline Material de uso e administração & $26.579,00$ & $26.579,00$ & $0,00 \%$ \\
\hline Material de Limpeza & $7.080,00$ & $7.080,00$ & $0,00 \%$ \\
\hline Telefonia+Internet & $8.428,90$ & $3.661,32$ & $-56,56 \%$ \\
\hline Contratos fixos & $66.049,00$ & $66.149,00$ & $0,15 \%$ \\
\hline Tarifas Públicas e Bancárias & $3.021,00$ & $2.300,00$ & $-23,87 \%$ \\
\hline Insumos Energéticos & $154.565,67$ & $125.637,43$ & $-18,72 \%$ \\
\hline Energia elétrica comum & $121.017,38$ & $123.137,43$ & $1,75 \%$ \\
\hline Energia elétrica - estação de tratamento água e esgoto & $3.548,29$ & - & $-100,00 \%$ \\
\hline Combustivel - Gerador & $30.000,00$ & $2.500,00$ & $-91,67 \%$ \\
\hline Serviços Públicos & $2.800,00$ & 356,27 & $-87,28 \%$ \\
\hline Água comum & $2.800,00$ & 356,27 & $-87,28 \%$ \\
\hline Taxa Administrativa & $37.380,00$ & $33.344,90$ & $-10,79 \%$ \\
\hline
\end{tabular}

Fonte: Elaborado pelos autores/2019 
Após a migração ao Mercado Livre o consumidor empresarial teve uma redução significativa em seus custos condominiais. É possível visualizar a discrepância entre os valores nos anos de 2016 e 2018, onde o primeiro ano base os custos com insumos energéticos contabilizam $\mathrm{R} \$ 154.565,67$, uma fatia de $23,28 \%$, após a adesão ao ACL houve a economia de R \$28.928,24 dentro do mês no mesmo período, tendo impacto significativo nas despesas. Possibilitando assim, a administração do empreendimento capital para possíveis investimentos.

\section{Resultados e Discursões}

O Setor Elétrico Brasileiro passou por grandes modificações em sua estrutura nos últimos 20 anos como foi apresentado na presente pesquisa, mudanças essas que foram necessárias e contribuíram para o crescimento econômico do país e modernização do setor elétrico nacional.

Com a criação do Ambiente de Contratação Regulada e o Ambiente de Contratação Livre pela forma de contratação de energia por meio de leilões, o novo modelo elétrico consegue estimular a expansão da geração de energia elétrica e consequentemente o crescimento da economia, como mais transparência quanto a atuação das distribuidoras as junto à população.

No ACR, os consumidores são obrigados a comprar energia da concessionaria local, que utilizam tarifas cobrada e regulada pela ANEEL, sofrendo ajuste anuais e revisões periódicas.

No ACL os consumidores potencialmente livres podem negociar o preço da energia diretamente com geradoras e agentes comercializadores, além de outras vantagens contratuais.

Segundo Tolmasquim (2015), o ambiente de comercialização livre de energia, onde os agentes podem negociar de forma livre os seus contratos, estabelecendo suas condições como período de fornecimento, preço e volume, torna o mercado livre atrativo, oferecendo benefícios como escolha, competitividade e previsibilidade, tanto o consumo como de custos. A presente pesquisa ratifica essa afirmativa através dos resultados obtidos comprovando a redução das tarifas de demanda de $\mathrm{R} \$ 17,99 \mathrm{~kW}$ para $\mathrm{R} \$ 8,99 \mathrm{~kW}$, energia incentivada com 
$50 \%$ de desconto, além das condições contratuais permitindo a livre negociação entre os agentes e a previsão dos custos energéticos para os próximos quatro anos.

Dentre os principais benefícios do mercado livre de energia estão os preços mais competitivos do que no mercado regulado, se beneficia com a maior previsibilidade orçamentária como observado nos resultados da pesquisa onde o consumo não tem alterações gritantes e com isso seus custos se mantêm, pois há uma demanda contratada para a necessidade do empreendimento e há a condução da energia elétrica como matéria prima, não ter diferenças de preço para horários de ponta e fora de ponta. Já no mercado cativo ocorrem alterações pela interferência dos horários de consumo em ponta e fora de ponta, o que deixa o consumidor sem previsibilidade dos gastos e paga mais caro por causa do desse sistema.

As contas de energia passaram a utilizar o sistema de bandeira tarifárias que indicam se a energia custa mais ou menos em função das condições de geração de eletricidade (ANEEL, 2017). No mercado livre o consumidor fica isento da oscilação das bandeiras tarifárias, como o estudo de caso comprovou através da redução dos custos, pois o mercado livre não se utiliza desse sistema de cálculos tendo como base os horários de consumo.

No objeto de estudo apresentado nessa pesquisa observou-se que ao migrar para o mercado livre, a unidade consumidora conseguiu economia de $18,46 \%, \mathrm{R} \$ 28.928,24$, além de retirar totalmente o gerador para horários de ponta, obtendo energia incentivada com $50 \%$ de desconto sobre a tarifa de demanda. Ressalta-se que a pesquisa é um estudo no qual se observa a vantagem da migração para o mercado livre por parte do consumidor. A previsibilidade e a utilização da vantagem da eficiência energética como mecanismos para redução dos custos operacionais.

Ainda tendo como vantagem ao retorno do investimento em menos de 28 dias, esclarecendo que a economia gerada em apenas um mês pode cobrir os custos de adaptação ao ACL.

Diante da exposição dessa pesquisa tem o resultado positivo com relação a relevância do Ambiente de Contratação Livre para o desenvolvimento comercial, industrial brasileiro. $\mathrm{O}$ mercado livre é uma alternativa real, viável e vantajosa para consumidores potencialmente livres.

301 Id on Line Rev. Mult. Psic. V.13, N. 46 p. 277-305, 2019 - ISSN 1981-1179 Edição eletrônica em http://idonline.emnuvens.com.br/id 


\section{Considerações Finais}

O objetivo deste artigo foi analisar a viabilidade financeira da migração para o mercado de energia elétrica livre, sob a ótica da gestão eficiente dos recursos financeiros em um condomínio varejista -shopping center que pertenceu ao mercado cativo, analisando as características e adequações necessárias a migração e a viabilidade econômico-financeira. Foi feito levantamento bibliográfico a respeito das características, vantagens e riscos de migração para o Mercado Livre de Energia Elétrica através de um estudo de caso. Em síntese, o estudo realizado demonstrou as características necessárias para a migração de consumidor cativo para livre.

Para o consumidor analisado nesta pesquisa, observa-se que os objetivos econômicos podem ser obtidos na migração para o mercado livre como consumidor especial, onde foi tomada uma decisão conservadora, um contrato médio de (4 anos), que darão a empresa uma previsibilidade de custos em um momento truculento com tendência e flutuação de preços no marcado cativo, principalmente pela instabilidade das chuvas.

$\mathrm{O}$ atrativo preço relacionado a migração, como por exemplo o contrato de demanda partindo de uma tarifa de $\mathrm{R} \$ 17,99$ para uma tarifa incentivada de $\mathrm{R} \$ 8,899$, tarifa ponta $\mathrm{R} \$$ 1,34 para $\mathrm{R} \$ 0,6962$, comtemplando toda a necessidade de fornecimento no horário de ponta, sem a necessidade de geração própria, além da liberdade de escolha do fornecedor de energia, trazem resultados também ao agregar valor ao empreendimento, pois optando por contratar energia na condição de consumidor livre especial, o consumidor está restrito a energia oriunda de pequenas centrais hidrelétricas (PCH's), energia de fontes renováveis como usinas eólicas, solares e de biomassa. Aliando assim Energia Livre a Energia limpa.

O estudo de caso aqui apresentado serviu para uma melhor fixação de todo o processo de transição, o ambiente de contratação livre proporciona a redução do custo frente ao mercado cativo, uma economia estimada em $\mathrm{R}$ \$ 27.879,96/mês e R \$ 334.559,52 ano, além de não está sujeito a variação de preço do mercado energético como por exemplo com bandeiras tarifarias, proporcionando uma melhor estratégia na definição dos custos e eficiente gestão dos recursos financeiros, sendo de extrema importância para garantir a sobrevivência e evolução competitivas dos envolvidos, lojistas, empreendedor e a administração do shopping. Mesmo com o investimento necessário para adequação do sistema de medição aos padrões da

302 Id on Line Rev. Mult. Psic. V.13, N. 46 p. 277-305, 2019 - ISSN 1981-1179 Edição eletrônica em http://idonline.emnuvens.com.br/id 
ONS, o estudo realizado através do payback mostra o retorno em apenas 27,53 dias, tornando totalmente viável.

A análise de investimentos envolve decisões de aplicação de recursos com prazos longos e curtos, com o objetivo de propiciar retorno adequado aos investidores desse recurso financeiro. Administradora do shopping em estudo levou em consideração que quanto maior tempo, maiores são as incertezas, procurando assim diminuir seus riscos optando por projetos que tenham um retorno do capital dentro de um período de tempo razoável. O retorno do investimento em 27,53 dias foi decisivo para a tomada de decisão, pois o playback é o período de tempo necessário para que as entradas de caixa do projeto se igualem ao valor a ser investido, ou seja, o tempo de recuperação do investimento realizado.

De maneira geral em relação ao ambiente cativo, o ambiente de contratação livre oferece preços atrativos de tarifas além da previsibilidade da despesa.

Foi constatado que é importante analisar a migração ao mercado livre todas as variáveis, sendo o principal o consumo que é o que determina todo o estudo de migração.

Com os resultados foi possível, então confirmar a viabilidade econômica financeira da migração, auxiliando na gestão eficiente dos recursos financeiros. Assim, o principal objetivo desde estudo foi alcançado, como discutido nas premissas do trabalho.

Com relação às limitações da pesquisa destaca-se o fato de esta investigação ter estudado apenas uma unidade consumidora que fez a migração do Mercado Cativo de Contratação de Energia Elétrica para o ambiente de Contratação Livre, não tendo a possibilidade de realizar análises comparativas. Neste sentido, como recomendações para a realização de futuras pesquisas, destaca-se a necessidade da realização de estudo de caso múltiplos, utilizando outras unidades consumidoras, modo a possibilitar uma análise comparativa para confirmar ou refutar a viabilidade financeira da migração entre mercados, sob a ótica da gestão eficiente de recursos financeiros.

\section{Referências}

ABRACEEL - Associação Brasileira dos Comercializadores de Energia. Cartilha do mercado livre de energia elétrica. Brasília: ABRACEEL, 2017. 
ABRACEEL - Associação Brasileira dos Comercializadores de Energia. Energia Livre: como a liberdade de escolha no setor elétrico pode mudar o Brasil. São Paulo, 2017.

ABRASCE - Associação Brasileia de Shopping Center. Disponível em: <https://abrasce.com.br/numeros/setor/>. Acessado em: 26 de março de 2019.

ANEEL - Agência Nacional de Energia Elétrica. Por dentro da conta de luz: Informação de utilidade pública. $7^{\mathrm{a}}$ ed. Brasília: 2017.

ASCONCELLOS, Marco Antônio S.; GARCIA, Manuel E. Fundamentos da economia. São Paulo: Saraiva, 2005.

CARDOSO, Marcos Vinicius Bragança; ROCHA, Jefferson Franco. Estudo sobre a viabilidade na migração para o mercado livre de energia. Revista Uningá, Jandaia do Sul, V.29, n.1, p. 37-46, jan-mar 2017.

CCEE - Câmara de Comercialização de Energia Elétrica. Comercialização de energia. 2017. Disponível em: <https://www.ccee.org.br/>. Acessado em: 21 fevereiro de 2019.

CHINAN, Luiz; NASSA, Thiago. Energia Livre: como a liberdade de escolha no setor elétrico pode mudar o Brasil. São Paulo: Associação Brasileira dos Comercializadores de Energia (ABRACEEL), 2014.

DURANTE, Guilherme. Estudo de migração de consumidor especial para o mercado livre de energia elétrica. Porto Alegre: UFRGS, 2016.

EPE - Empresa de Pesquisa Energética. Anuário Estatístico de Energia Elétrica 2017: ano base 2016. Disponível em: >http://www.epe.gov.br/sites-pt/publicacoes-dadosabertos/publicacoes/PublicacoesArquivos/publicacao-160/topico-168/Anuario2017vf.pdf<. Acessado em: 10 de março de 2019.

GENERGIA. Tudo sobre o mercado livre de energia. João Pessoa: GENERGIA, 2016.

GIL, Antonio Carlos. Como elaborar projetos de pesquisa. 4. ed. São Paulo: Atlas, 2002.

INTERNATIONAL COUNCIL OF SHOPPING CENTERS. Conceitos Financeiros. Tradução Cecília Regina Pernambuco; Aldyr Scuri. Rio de Janeiro: ABRASCE, 2003.

JÚNIOR, Álvaro Domingos Malzoni; et.al. Administração de shopping centers: Plaza Shopping Empreendimentos Ltda. São Paulo: UNISALESIANO, 2009.

OLIVEIRA, Yasmin Martins de. O mercado livre de energia no Brasil: Aprimoramentos para sua expansão. Brasília: UnB, 2017.

RAUPP, F.M.; BEUREN, I.M. Metodologia da pesquisa aplicável às ciências sociais. 3.ed. São Paulo: Atlas, 2006. Disponível em: 
RIZKALLA, Felipe Farage. Migração para o mercado livre de energia: estudo de caso do Centro de Tecnologia da Universidade Federal do Rio de Janeiro. Rio de Janeiro: UFRJ, 2018.

SANTOS, Givaldo; JUNIOR, Samuel Fereira; ORTIZ, Edgard. Lojas em shopping centers: análise do custo operacional como fator de sobrevivência e competitividade em lojas de alimentação. Revista de Tecnologia Aplicada (RTA), v.4, n.3, p. 3-20, set-dez, 2015.

SHOR, Juliana Melcop. Abertura do mercado livre de energia elétrica: vantagens e Possibilidade do Retail Wheeling no Brasil. Rio de Janeiro: Synergia, 2018.

TOLMASQUIM, Mauricio T. Novo modelo do setor elétrico brasileiro. $2^{\mathrm{a}}$ ed. Rio de Janeiro: Synergia; EPE: Brasília, 2015.

VERGARA, Sylvia Constant. Projetos e relatórios de pesquisa em Administração. $16^{\mathrm{a}}$ ed. São Paulo: Atlas, 2016.

\section{Como citar este artigo (Formato ABNT):}

COSTA, Crislane Soare; OLIVERA, Elane Lopes de; SOUSA, Josiano Cesar de. O mercado brasileiro de Energia Elétrica Livre: um estudo de caso na indústria de Shopping Center sob a ótica da gestão eficiente dos recursos financeiros. Id on Line Rev.Mult. Psic., 2019, vol.13, n.46, p. 277-305. ISSN: 1981-1179.

Recebido: 07/06/2019

Aceito 13/06/2019 